\title{
Identifying female pelvic cancer survivors with low levels of physical activity after radiotherapy: women with fecal and urinary leakage need additional support
}

\author{
Anna Lindgren ${ }^{1}$ (D) $\cdot$ G. Dunberger ${ }^{2} \cdot$ G. Steineck ${ }^{3,4} \cdot$ K. Bergmark $^{4} \cdot$ A. Enblom ${ }^{5}$ \\ Received: 25 January 2019 / Accepted: 8 August 2019 / Published online: 22 October 2019 \\ (C) The Author(s) 2019
}

\begin{abstract}
Objective To investigate the frequency of physical activity among female pelvic cancer survivors (i.e., gynecological, rectal, and anal cancer survivors) and to investigate if survivors who practiced physical activity less than once a week differed from survivors practicing physical activity at least once a week with respect to urinary and fecal leakage, clinical and sociodemographic characteristics, quality of life (QoL), and depressed and anxious mood.

Methods Female pelvic cancer survivors ( $n=578$, mean age 64 years) answered a questionnaire 6-48 months after radiotherapy. A multivariable regression model analyzed factors covarying with frequency of physical activity. We compared QoL and depressed and anxious mood between women practicing physical activity at least or less than once a week.

Results Of 568 women delivering data, 186 (33\%) practiced physical activity less than once a week while $382(67 \%)$ practiced physical activity at least weekly. Women who leaked a large or all volume of stools $(p=0.01)$, had just elementary school level of education $(p<0.001)$, smokers $(p=0.049)$, or had lymphedema without receiving lymphedema treatment $(p=0.030)$ were more likely to practice physical activity less than weekly $(50 \%, 45 \%, 45 \%$, and $37 \%$, respectively) compared with other women. Women practicing physical activity at least weekly reported better QoL $(p<0.001)$ and lower frequency of depressed $\operatorname{mood}(p=$ 0.044) compared with the others.

Conclusions Female cancer survivors experiencing fecal leakage were less likely to practice weekly physical activity than survivors without leakage. The survivors practicing weekly physical activity experienced better QoL and experienced depressed mood less frequently than the others.
\end{abstract}

Keywords Colorectal cancer $\cdot$ Fecal leakage $\cdot$ Gynecological cancer $\cdot$ Incontinence $\cdot$ Physical activity $\cdot$ Urinary leakage

Anna Lindgren

anna.lindgren@liu.se

1 County Council of Östergötland and Department of Medical and Health Sciences, Division of Physiotherapy, Linköping University, SE-58183 Linköping, Sweden

2 Department of Health Care Sciences, Ersta Sköndal University College, Stockholm, Sweden

3 Department of Oncology-Pathology, Division of Clinical Cancer Epidemiology, Karolinska Institute, Stockholm, Sweden

4 Department of Clinical Sciences, Division of Clinical Cancer Epidemiology, Sahlgrenska Academy, Gothenburg University, Gothenburg, Sweden

5 County Council of Östergötland, Activity and Health and Division of Coordinated Cancer Evaluation, Department of Medical and Health Sciences, Linköping University, Linköping, Sweden

\section{Introduction}

Several studies have found that physical activity results in health benefits for cancer survivors [1], but few studies [2-4] have investigated the adherence to and potential barriers to physical activity in female cancer survivors after pelvic radiotherapy. Physical activity means bodily movement produced by skeletal muscles that require energy expenditure [5]. Previous studies observed that physical activity in cancer survivors can produce a variety of beneficial health effects $[1,6]$ and has a relationship with reduced risk of recurrence and mortality in cancer, for example, ovarian cancer, breast cancer, colon cancer, and rectal cancer [7, 8]. A risk reduction of $37 \%$ in cancer-specific mortality was reported in a review comparing patients who were most physically active with those who were least physically active based on 26 studies of breast, colorectal, and prostate cancer [9]. 


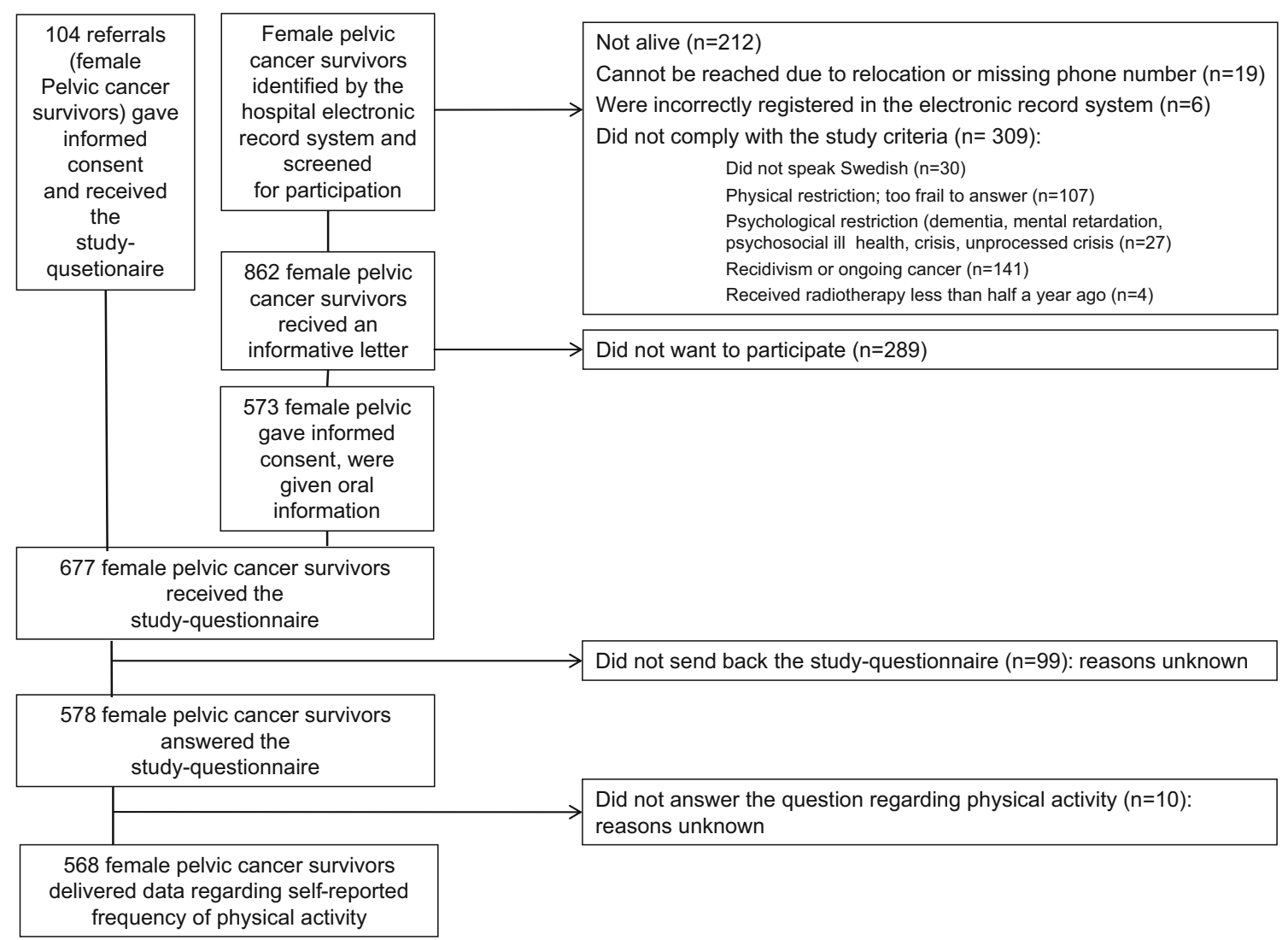

Fig. 1 Flowchart of the screened, included and responding female pelvic cancer survivors

Reports of increasing numbers of observed health benefits of physical activity in cancer survivors $[1,6]$ have led to guidelines regarding physical activity in cancer survivors [10], underscoring the importance of exercise in cancer rehabilitation. In Sweden [11] and other countries [10], guidelines recommend at least $150 \mathrm{~min}$ of moderate intensity physical activity, or $75 \mathrm{~min}$ of vigorous physical activity, weekly. Despite strong evidence for the health benefits of physical activity in cancer survivors $[1,6]$, many survivors do not adhere to the guidelines $[3,4,12,13]$. Cancer survivors in general tend to decrease their level of physical activity compared with the level pre-cancer treatment [14]. With pelvic cancer, survival is meant in the present study gynecological, rectal, and anal cancer survivors. Colorectal cancer survivors reported a low frequency of physical activity and high volume of sedentary time after cancer treatment [15]. Thirteen percent of gynecological cancer survivors stated that they never practiced physical activity after cancer treatment [2].

Radiotherapy is an important life-saving part of cancer treatment. However, radiotherapy induces an inflammatory process that can lead to fibrosis and thereby reduces elasticity and activation of the pelvic floor muscles. In addition, radiotherapy often induces nerve damages and reduces blood flow within the muscular tissues, which further may complicate muscular activation and may cause atrophy [16]. Symptoms that occur or persist for more than 3 months after radiotherapy are referred to as late side effects. These long-term unwanted pathophysiological consequences of radiotherapy [17, 18] often lead to urinary and fecal leakage [2, 18-21]. Fecal and urinary leakage is one of the most serious late consequences of pelvic radiotherapy that complicates life and aging [19-21]. Fecal leakage is also defined as the leakage syndrome [18]. Our [18] and others' $[16,17]$ data indicate treatment-induced late consequences may be lifelong.

In a previous qualitative study, female pelvic cancer survivors experienced leakage to be a barrier for practicing physical activity, especially if there was no bathroom nearby. Lack of physical activity decreased their psychological energy and physical fitness [22]. Based on observations from noncancer female populations [23], it is plausible that leakage may be a barrier for pelvic cancer survivors keeping them from practicing physical activity. However, according to our database searches, no previous quantitative studies have explored the frequency of physical activity in relation to urinary or fecal leakage among female pelvic cancer survivors (www. ncbi.nlm.nih.gov/pubmed, search terms (physical activity) AND cancer AND (incontinence OR leakage), date 12.11.18).

The objective of our study was to investigate frequency of physical activity among female pelvic cancer survivors after radiotherapy and to investigate if survivors who practiced 
Table 1 Characteristics of the study participants

\begin{tabular}{ll}
\hline Variable & $\begin{array}{l}\text { Total study group of female pelvic } \\
\text { cancer survivors, } n=578\end{array}$
\end{tabular}

\begin{tabular}{|c|c|}
\hline Cancer type, $n(\%)$ & \\
\hline Gynecological cancer & $367(63)$ \\
\hline Rectal cancer & $131(23)$ \\
\hline Anal cancer & $77(13)$ \\
\hline Other & $3(1)$ \\
\hline Age in years, mean $\pm \mathrm{SD}$ & $\begin{array}{l}n=577 \\
64 \pm 12.9\end{array}$ \\
\hline $\begin{array}{l}\text { Years since radiotherapy, mean } \\
\quad \pm \mathrm{SD}\end{array}$ & $\begin{array}{l}n=576 \\
2.7 \pm 3.4\end{array}$ \\
\hline Cancer treatment, $n(\%)$ & $n=577$ \\
\hline External radiotherapy, only & $131(23)$ \\
\hline Brachytherapy, only & $1(0.2)$ \\
\hline $\begin{array}{l}\text { External radiotherapy and } \\
\text { brachytherapy }\end{array}$ & $20(3)$ \\
\hline $\begin{array}{l}\text { External radiotherapy, } \\
\text { brachytherapy and surgery }\end{array}$ & $178(31)$ \\
\hline $\begin{array}{l}\text { External radiotherapy and } \\
\text { surgery }\end{array}$ & $243(42)$ \\
\hline Brachytherapy and surgery & $4(0.6)$ \\
\hline Marital status, $n(\%)$ & \\
\hline $\begin{array}{l}\text { Married or living with a } \\
\text { partner }\end{array}$ & $386(67)$ \\
\hline Widow & $66(11)$ \\
\hline Has a partner but lives alone & $28(5)$ \\
\hline Single & $98(17)$ \\
\hline Education level, $n(\%)$ & $n=569$ \\
\hline Elementary school & $171(30)$ \\
\hline Secondary school & $211(36)$ \\
\hline Collage/university & $187(32)$ \\
\hline Employment status, $n(\%)$ & $n=573$ \\
\hline Student & $4(0.6)$ \\
\hline Unemployed job seeker & $11(2)$ \\
\hline Employed, n (\%) & $161(28)$ \\
\hline Home maker & $4(0.6)$ \\
\hline On sick leave & $48(8)$ \\
\hline Disability pension & $31(5)$ \\
\hline Retired & $314(54)$ \\
\hline Resident, $n(\%)$ & $n=577$ \\
\hline On the countryside & $108(19)$ \\
\hline Small or medium-sized city & $297(51)$ \\
\hline In a big city & $172(30)$ \\
\hline Smoking, $n(\%)$ & $n=555$ \\
\hline Yes & $66(11)$ \\
\hline No & $489(85)$ \\
\hline
\end{tabular}

$n$ (number) and proportion (\%) of women are presented, $n$ delivering data is presented in case of missing data. $\mathrm{SD}=$ standard deviation

physical activity less than once a week differed from survivors practicing physical activity at least once a week regarding urinary and fecal leakage, clinical and sociodemographic characteristics, quality of life, and depressed and anxious mood.

\section{Methods}

\section{Setting and inclusion}

The setting was outpatient in southwest Sweden. By examining the electronic records, a nurse, at a rehabilitation unit at a university hospital, identified female pelvic cancer survivors who had received pelvic radiotherapy between 2007 and 2016. The rehabilitation unit also received referrals from within and outside the university hospital. The identified or referred pelvic cancer survivors were screened for the study criteria. Inclusion criteria: Received external pelvic radiotherapy with or without intracavity brachytherapy for gynecological, rectal, or anal cancer 6-48 months ago. Exclusion criteria: Ongoing cancer, physical, psychological, or linguistic (not understanding Swedish) issues that made it difficult for them to give informed consent.

An information letter offered a follow-up visit unit for support regarding radiotherapy-induced consequences. To document potential consequences, the information letter asked the survivors to answer a study-specific questionnaire, attached with the information letter, data from which was used in this study. The regional ethics committee approved the study (Gothenburg 686-10), which adhered to the declaration of Helsinki.

\section{The study-specific questionnaire}

The study-specific questionnaire (Appendix) was developed and satisfactorily validated according to clinimetric methodology $[2,24]$, frequently applied when studying cancer survivors $[2,20,25]$. Details of the validation procedure have been previously reported [2].

\section{Sociodemographic and clinical characteristics}

The women reported sociodemographic and clinical characteristics and a nurse collected data on previous cancer diagnoses and radiotherapy data from the medical records.

\section{Frequency of physical activity}

The women answered the question: "Do you practice physical activity?" (Seven categories ranging from "No to "Yes, at least once a day"). The question correlated well to the Swedish Board of Welfare and Health indicator question regarding moderate level physical activity (Spearman's correlation coefficient, $r_{\mathrm{s}}, 0.556, n=449$ ), which is valid compared with accelerometer-measured activity [26]. The women were 
Table 2 Frequency of physical activity in female pelvic cancer survivors with various severities of urinary leakage

\begin{tabular}{|c|c|c|c|}
\hline Variable & $\begin{array}{l}\text { Practicing physical activity at least } \\
\text { once a week, } n=382\end{array}$ & $\begin{array}{l}\text { Practicing physical activity less than } \\
\text { once a week, } n=186\end{array}$ & $\begin{array}{l}\text { Relative risk, } 95 \% \text { CI, } p \\
\text { value, } n=568\end{array}$ \\
\hline $\begin{array}{l}\text { Frequency of leakage in case of urgency, } n \\
(\%)\end{array}$ & $n=374$ & $n=182$ & \\
\hline No & $220 / 310(71)$ & $90 / 310(29)$ & Ref. \\
\hline Occasionally & $105 / 162(65)$ & $57 / 162(35)$ & $1.21,0.14-0.92,0.166$ \\
\hline At least once a month & $10 / 20(50)$ & $10 / 20(50)$ & $1.72,1.07-2.76,0.024 *$ \\
\hline At least once a week & $17 / 24(70)$ & $7 / 24(29)$ & $1.0,0.53-1.92,0.989$ \\
\hline At least three times a week & $9 / 13(69)$ & $4 / 13(31)$ & $1.06,0.46-2.44,0.891$ \\
\hline At least once a day & $13 / 27(48)$ & $14 / 27(52)$ & $1.79,1.19-2.67,0.005^{*}$ \\
\hline Volume of leakage, $n(\%)$ & $n=371$ & $n=177$ & \\
\hline No leakage & $193 / 262(74)$ & $69 / 262(26)$ & Ref. \\
\hline Small volume of urine & $132 / 207(63)$ & $75 / 207(36)$ & $1.38,1.05-1.80,0.021 *$ \\
\hline Large volume of urine & $37 / 63(59)$ & $26 / 63(41)$ & $1.57,1.10-2.24,0.014 *$ \\
\hline All volume of urine & $5 / 11(45)$ & $6 / 11(55)$ & $2.10,1.16-3.69,0.014 *$ \\
\hline $\begin{array}{l}\text { Capacity to hold urine before leakage in } \\
\text { case of urgency, } n(\%)\end{array}$ & $n=366$ & $n=178$ & \\
\hline At least $30 \mathrm{~min}$ & $56 / 76(74)$ & $20 / 76(26)$ & Ref. \\
\hline $10-30 \mathrm{~min}$ & $89 / 124(72)$ & $35 / 124(28)$ & $1.07,0.67-1.72,0.77$ \\
\hline $5-10 \mathrm{~min}$ & $92 / 127(72)$ & $35 / 127(28)$ & $1.05,0.65-1.68,0.847$ \\
\hline $1-5 \mathrm{~min}$ & $96 / 143(67)$ & $47 / 143(33)$ & $1.25,0.80-1.95,0.326$ \\
\hline Less than $1 \mathrm{~min}$ & $33 / 74(45)$ & $41 / 74(55)$ & $2.11,1.37-3.23,<0.001 *$ \\
\hline
\end{tabular}

$n$ (number) and proportion (\%) of women are presented, $n$ delivering data is presented in case of missing data. Ref. = Reference category, relative risk 1.0; the category free from or with lowest severity of leakage. $\mathrm{CI}=95 \%$ confidence interval, *statistically significant difference. The time frame of the questions was the past 6 months

not given any definition of physical activity before answering the question but were free to interpret the question from their own perception of physical activity.

\section{Urinary and fecal leakage}

The questionnaire asked about urinary leakage, one example being: "Have you been wetting yourself because you could not reach the toilet in time within the past six months?" (Six categories, "No" to "Yes, at least once a day"), and "How large volume do you leak? (Four categories, "Not applicable," to "All bladder volume"). The questionnaire asked about fecal leakage, one example being: "Have you leaked stools because you could not reach the toilet in time, within the past six months?" (Six categories, "No" to "Yes, at least daily"), and "How large volume do you leak? (Four categories, "Not applicable, I do not leak stool" to "All volume of stools").

\section{Quality of life and depressed and anxious mood}

The women graded their experienced quality of life and their level of depressed and anxious mood on 7-point numeric rating scales: "How has your quality of life been the last six months? ("No quality of life at all" to "Best possible quality of life"), "Have you felt low or depressed within the past six months?", and "Have you felt anxious within the past six months?" ("Never" to "All the time"). These questions demonstrated high co-variation and consistency with established instruments [27].

\section{Statistical analysis}

We calculated descriptive data: number $(n)$ and proportions (percent) for all variables, mean value with standard deviation ( $\pm 1 \mathrm{SD})$ for continuous variables, and median (md) with 25 th and 75th percentiles (IQR) for ordinal variables. We categorized the physical activity data into two groups: "Practiced physical activity at least once a week" (i.e., "Yes, at least once a week," "Yes, at least three times a week," and "Yes, at least once a day") and "Practiced physical activity less than once a week" ("No," "Yes, occasionally," "Yes, at least once a month"), based on guidelines [9] that recommend weekly physical activity. Fisher's exact test compared subgroups with different characteristics regarding urinary and fecal leakage, and sociodemographic and clinical variables, presented as relative risks (RR) for practicing physical activity less than once a week, with $95 \%$ confidence intervals (CI). The reference category was defined as the category with the lowest proportion not practicing physical activity at least once a week. We selected volume of fecal and urinary leakage and other possible sociodemographic and clinical variables (all variables seen in Table 4 resulting in a $p$ value of $<0.10$, according to the univariable analysis) explaining the variation of physical activity with a multivariable generalized linear model, and generated relative risks using binomial distribution and log link. A response analysis was also made to ensure that the loss in the multivariable analysis did not affect its results. We compared the physical activity groups using Mann-Whitney $U$ test regarding quality of life, depressed mood, and anxious mood 
Table 3 Frequency of physical activity in female pelvic cancer survivors with various severities of fecal leakage

\begin{tabular}{|c|c|c|c|}
\hline Variable & $\begin{array}{l}\text { Practicing } \\
\text { physical } \\
\text { activity at least } \\
\text { once a week, } \\
n=382\end{array}$ & $\begin{array}{l}\text { Practicing } \\
\text { physical } \\
\text { activity less } \\
\text { than once } \\
\text { a week, } \\
n=186\end{array}$ & $\begin{array}{l}\text { Relative risk, } \\
95 \% \mathrm{CI}, p \text { value, } \\
n=568\end{array}$ \\
\hline $\begin{array}{l}\text { Frequency of leakage } \\
\text { in case of urgency, } \\
n(\%)\end{array}$ & $n=365$ & $n=170$ & \\
\hline No & $155 / 223(68)$ & $68 / 223(30)$ & Ref. \\
\hline Occasionally & $135 / 194(70)$ & $59 / 194(30)$ & $\begin{array}{l}1.00,0.75-1.33 \\
0.986\end{array}$ \\
\hline $\begin{array}{l}\text { At least once a } \\
\text { month }\end{array}$ & $26 / 40(65)$ & $14 / 40(35)$ & $\begin{array}{l}1.15,0.72-1.83 \text {, } \\
0.563\end{array}$ \\
\hline At least once a week & $33 / 47(70)$ & $14 / 47(30)$ & $\begin{array}{l}0.98,0.60-1.58 \\
0.924\end{array}$ \\
\hline $\begin{array}{l}\text { At least three times a } \\
\text { week }\end{array}$ & $11 / 18(61)$ & $7 / 18(39)$ & $\begin{array}{l}1.28,0.69-2.35 \\
0.436\end{array}$ \\
\hline At least once a day & $5 / 13(39)$ & $8 / 13(62)$ & $\begin{array}{l}2.02,1.26-3.24 \\
0.004 *\end{array}$ \\
\hline $\begin{array}{l}\text { Volume of leakage, } n \\
\quad(\%)\end{array}$ & $n=360$ & $n=172$ & \\
\hline No leakage & $156 / 223(70)$ & $67 / 223(30)$ & Ref. \\
\hline Just soiling & $103 / 147(70)$ & $44 / 147(30)$ & $\begin{array}{c}1.0,0.72-1.37 \\
0.982\end{array}$ \\
\hline $\begin{array}{l}\text { Small volume of } \\
\text { stools }\end{array}$ & $74 / 110(67)$ & $36 / 110$ & $\begin{array}{l}1.1,0.78-1.52 \\
0.616\end{array}$ \\
\hline $\begin{array}{l}\text { Large volume of } \\
\text { stools }\end{array}$ & 20/41 (49) & $21 / 41(51)$ & $\begin{array}{l}1.70,1.19-2.44 \\
0.004 *\end{array}$ \\
\hline All stools & $7 / 11(64)$ & 4/11 (36) & $\begin{array}{l}1.21,0.54-2.71, \\
0643\end{array}$ \\
\hline $\begin{array}{l}\text { Leakage of all stools } \\
\quad \text { without } \\
\text { forewarning, } n(\%)\end{array}$ & $n=364$ & $\mathrm{n}=177$ & \\
\hline No & $315 / 448(70)$ & $133 / 448(30)$ & Ref. \\
\hline Yes & $49 / 98(50)$ & $49 / 98(50)$ & $\begin{array}{l}1.68,1.32-2.15 \\
\quad<0.001^{*}\end{array}$ \\
\hline
\end{tabular}

$n$ (number) and proportion (\%) of women are presented, $n$ delivering data is presented in case of missing data. Ref. $=$ Reference category, relative risk 1.0; the category free from leakage. $\mathrm{CI}=95 \%$ confidence interval, *statistically significant difference. The time frame of the questions was the past 6 months

(ordinal variables). The analyses were performed in Statistical Package of Social Science (SPSS) for Windows, version 24.0, and the significance level was $5 \%$.

\section{Results}

\section{The participating women}

Of the 677 female pelvic cancer survivors who were included and received the study questionnaire, 99 did not answer the questionnaire, while 578 answered (response rate 85\%) and $568(98 \%)$ of the answering women provided data regarding physical activity (Fig. 1). Mean age was 64 years. Table 1 presents clinical and demographic characteristics.

\section{Frequency of physical activity}

Of 568 women provided data regarding physical activity; 68 (12\%) never practiced physical activity, 101 (18\%) occasionally (at single occasions), 17 (3\%) at least once a month, $160(28 \%)$ at least once a week, 160 (23\%) at least three times a week, and 92 (16\%) practiced physical activity at least once a day. Accordingly, $383(67 \%)$ practiced physical activity at least once a week while $186(33 \%)$ practiced physical activity less than once a week.

\section{Physical activity in women with or without urinary leakage}

Of the 27 women who reported daily urinary leakage in case of urgency, 52\% practiced physical activity less than once a week, compared with $29 \%$ of the 310 women who reported no urinary leakage when answering a question regarding frequency of urinary leakage ( $p=0.005$, Table 2$)$. Of the 74 women who could keep urine less than a minute in case of urgency, $55 \%$ practiced physical activity less than once a week, compared with $26 \%$ of the 76 women who could keep urine more than $30 \mathrm{~min}(p<0.001$, Table 2$)$. Furthermore, of the 74 women who reported a moderate to all volume of leakage, $32 \%$ practiced physical activity less than once a week, compared with $27 \%$ of the 266 women who reported no volume of urinary leakage when answering a question regarding volume of urinary leakage ( $p=0.04$, crude models, Table 4$)$. However, when adding the other independent variables into the analysis, for example, volume of fecal leakage, the relationship between urinary leakage and the dependent variable frequency of practicing physical activity was not significant $(p=0.105$, adjusted models, Table 4). According to the response analysis, the loss in the multivariable analysis did not affect its results.

\section{Physical activity in women with or without fecal leakage}

Of the 13 women who reported daily fecal leakage in case of urgency, $62 \%$ practiced physical activity less than once a week, compared with $30 \%$ of the 223 women with no fecal leakage when answering a question regarding frequency of fecal leakage $(p=0.004)$. Of the 98 women who reported fecal leakage without forewarning anytime within the preceding 6 months, $50 \%$ practiced physical activity less than once a week $(p<0.001)$, compared with $30 \%$ of the 448 women who did not report any fecal leakage without forewarning when answering a question regarding volume of fecal leakage (Table 3). Of the 54 women who reported a large or all volume of fecal leakage, $50 \%$ practiced physical activity less than once a week compared with $31 \%$ of the 388 women with no volume of fecal leakage or just soiling when answering a question regarding volume of fecal leakage ( $p=0.002$, crude models, Table 4 ). When adding the other independent variables into the analysis, 
Table 4 Frequency of physical activity in subgroups of female pelvic cancer survivors with or without fecal or urinary leakage and with a variety of sociodemographic and clinical characteristics

\begin{tabular}{|c|c|c|c|c|}
\hline Variable & $\begin{array}{l}\text { Practicing physical } \\
\text { activity at least once a } \\
\text { week, } n=382\end{array}$ & $\begin{array}{l}\text { Practicing physical } \\
\text { activity less than once a } \\
\text { week, } n=186\end{array}$ & $\begin{array}{l}\text { Relative risk, } 95 \% \mathrm{CI}, p \text { value } \\
\text { univariable analyses (crude } \\
\text { models), } n=568\end{array}$ & $\begin{array}{l}\text { Relative risk, } 95 \% \text { CI, } p \text { value } \\
\text { multivariable analysis (adjusted } \\
\text { models), } n=492\end{array}$ \\
\hline Urinary leakage, $n(\%)$ & $n=369$ & $n=178$ & $n=547$ & \\
\hline No leakage & $195 / 266(73)$ & $71 / 266(27)$ & Ref. & Ref. \\
\hline Small leakage & $132 / 207(64)$ & $75 / 207(36)$ & $1.36,1.04-1.78,0.026^{*}$ & $1.17,0.89-1.54,0.261$ \\
\hline $\begin{array}{l}\text { Moderate to large, i.e., } \\
\text { moderate, large, or all } \\
\text { volume }\end{array}$ & $42 / 74(57)$ & $32 / 74(43)$ & $1.62,1.17-2.25,0.04 *$ & $1.33,0.942-1.889,0.105$ \\
\hline Fecal leakage, $n(\%)$ & $n=369$ & $n=183$ & $n=552$ & \\
\hline $\begin{array}{l}\text { No leakage, i.e., no leakage or } \\
\text { just soiling }\end{array}$ & $268 / 388(69)$ & $120 / 388(31)$ & Ref. & Ref. \\
\hline Small leakage & $74 / 110(67)$ & $36 / 110(33)$ & $1.06,0.78-1.44,0.72$ & $1.02,0.75-1.38,0.91$ \\
\hline $\begin{array}{l}\text { Large volume, i.e., large or all } \\
\text { volume }\end{array}$ & $27 / 54(50)$ & $27 / 54(50)$ & $1.62,1.19-2.19,0.002 *$ & $1.54,1.11-2.15,0.01 *$ \\
\hline \multicolumn{5}{|l|}{ Cancer type, $n(\%)$} \\
\hline Gynecological cancer & $230 / 359(64)$ & $129 / 359(36)$ & $1.32,1.02-1.71,0.034 *$ & $1.26,0.96-1.65,0.097$ \\
\hline Not gynecological cancer & $152 / 209(73)$ & $57 / 209(27)$ & Ref. & Ref. \\
\hline Age in years, $n(\%)$ & $n=382$ & $n=183$ & & \\
\hline $24-45$ & $39 / 59(66)$ & $20 / 59(34)$ & $1.08,0.71-1.62,0.710$ & Not applicable ${ }^{5}$ \\
\hline $46-65$ & $153 / 223(69)$ & $70 / 223(31)$ & Ref. & \\
\hline $66-94$ & $190 / 286(66)$ & $96 / 286(34)$ & $1.07,0.83-1.38,0.604$ & Not applicable ${ }^{5}$ \\
\hline Year since radiotherapy, $n(\%)$ & $n=381$ & $n=186$ & & \\
\hline Less than 1 year ago & $151 / 227(67)$ & $76 / 227(33)$ & $1.13,0.66-1.91,0.66$ & Not applicable ${ }_{5}^{5}$ \\
\hline $1-5$ years ago & $204 / 303(67)$ & $99 / 303(33)$ & $1.10,0.65-1.85,0.723$ & Not applicable $^{5}$ \\
\hline More than 5 years ago & $26 / 37(70)$ & $11 / 37(30)$ & Ref. & \\
\hline Cancer treatment, $n(\%)$ & $n=258$ & $n=114$ & & \\
\hline External radiotherapy, only & $79 / 130(61)$ & $51 / 130(39)$ & $1.24,0.89-1.73,0.20$ & Not applicable ${ }^{5}$ \\
\hline $\begin{array}{l}\text { External radiotherapy and } \\
\text { surgery }\end{array}$ & $174 / 237(73)$ & $63 / 237(27)$ & Ref. & \\
\hline Brachytherapy and surgery & $5 / 5(100)$ & $0 / 5(0)$ & Not applicable $^{1}$ & \\
\hline Marital status, $n(\%)$ & $n=382$ & $n=186$ & & \\
\hline $\begin{array}{l}\text { Married, living together, or } \\
\text { has a partner }\end{array}$ & $285 / 408(70)$ & $123 / 408(30)$ & Ref. & Ref. \\
\hline Widow or single & $97 / 160(61)$ & $63 / 160(39)$ & $1.311 .02-1.66,0.031 *$ & $1.24,0.97-1.60,0.091$ \\
\hline Education level, $n(\%)$ & $n=378$ & $n=183$ & & \\
\hline Elementary school & $90 / 164(55)$ & $74 / 164(45)$ & $1.64,1.30-2.07,<0.001 *$ & $1.62,1.27-2.01,<0.001 *$ \\
\hline $\begin{array}{l}\text { Secondary school, college or } \\
\text { university }\end{array}$ & $288 / 397(73)$ & $109 / 397(27)$ & Ref. & Ref. \\
\hline Employment status, $n(\%)$ & $n=379$ & $n=184$ & & \\
\hline Unemployed job seeker & $3 / 11(27)$ & 8/11 (73) & $2.32,1.52-3.56,<0.001 *$ & Not applicable $^{1}$ \\
\hline $\begin{array}{l}\text { Employed, housewife/man, } \\
\text { or student }\end{array}$ & $116 / 169(69)$ & $53 / 169(31)$ & Ref. & \\
\hline On sick leave & $30 / 48(63)$ & $18 / 48(37)$ & $1.20,0.78-1.83,0.413$ & Not applicable ${ }_{5}^{5}$ \\
\hline $\begin{array}{l}\text { Retired due to age or } \\
\text { disability }\end{array}$ & $230 / 335(69)$ & $105 / 335(31)$ & $1.0,0.76-1.31,0.999$ & Not applicable ${ }^{5}$ \\
\hline Resident, $n(\%)$ & $n=381$ & $n=186$ & & \\
\hline On the countryside & $65 / 106(61)$ & $41 / 106(39)$ & $1.23,0.93-1.62,0.141$ & Not applicable ${ }^{5}$ \\
\hline In a small or big city & $316 / 461(69)$ & $145 / 461(31)$ & Ref. & \\
\hline Smoking, $n(\%)$ & $n=370$ & $n=177$ & & \\
\hline Yes & $36 / 66(55)$ & $30 / 66(45)$ & $1.49,1.10-2.00,0.009^{*}$ & $1.34,1.00-1.79,0.049^{*}$ \\
\hline No & $334 / 481(69)$ & $147 / 481(31)$ & Ref. & Ref. \\
\hline Weight change $^{3}, n(\%)$ & $n=337$ & $n=151$ & & \\
\hline No & $118 / 164(72)$ & $46 / 164(28)$ & Ref. & \\
\hline Yes, weight gain & $81 / 119(68)$ & $38 / 119(32)$ & $1.13,0.82-1.56,0.453$ & Not applicable ${ }^{5}$ \\
\hline Yes, weight loss & $138 / 205(67)$ & $67 / 205(33)$ & $1.27,0.93-1.74,0.131$ & Not applicable ${ }^{5}$ \\
\hline Pain in the abdomen ${ }^{2}, n(\%)$ & $n=370$ & $n=184$ & & \\
\hline Less than once a day & $345 / 509(68)$ & $164 / 509(32)$ & Ref. & Ref. \\
\hline At least once a day & $25 / 45(56)$ & $20 / 45(44)$ & $1.38,0.97-1.96,0.072$ & $1.30,0.89-1.904,0.17$ \\
\hline $\begin{array}{l}\text { Lymphedema diagnose and } \\
\text { treatment, } n(\%)\end{array}$ & $n=386$ & $n=174$ & & \\
\hline No lymphedema diagnose & $269 / 402(67)$ & $133 / 402(33)$ & $2.22,1.11-4.46,0.025^{*}$ & $2.02,1.02-4.02,0.045^{*}$ \\
\hline
\end{tabular}


Table 4 (continued)

\begin{tabular}{lllll}
\hline Variable & $\begin{array}{l}\text { Practicing physical } \\
\text { activity at least once a } \\
\text { week, } n=382\end{array}$ & $\begin{array}{l}\text { Practicing physical } \\
\text { activity less than once a } \\
\text { week, } n=186\end{array}$ & $\begin{array}{l}\text { Relative risk, 95\% CI, } p \text { value } \\
\text { univariable analyses (crude } \\
\text { models), } n=568\end{array}$ & $\begin{array}{l}\text { Relative risk, 95\% CI, } p \text { value } \\
\text { multivariable analysis (adjusted } \\
\text { models), } n=492\end{array}$ \\
\hline $\begin{array}{c}\text { Lymphedema diagnose but } \\
\text { has not received any } \\
\text { treatment }\end{array}$ & $59 / 93(63)$ & $34 / 93(37)$ & $2.45,1.18-5.11,0.017 *$ & $2.25,1.08-4.67,0.030^{*}$ \\
$\begin{array}{c}\text { Lymphedema diagnose and } \\
\text { received treatment }{ }^{4}\end{array}$ & $40 / 47(85)$ & $7 / 47(15)$ & Ref. & Ref. \\
\hline
\end{tabular}

$n$ (number) and proportion (\%) of women are presented, $n$ delivering data is presented in case of missing data. Ref. = Reference category, relative risk 1.0; the category with the lowest proportion practicing physical activity less than once a week. CI $=95 \%$ confidence interval, *statistically significant difference. ${ }^{1}$ Due to low $n ;{ }^{2}$ Within the last 6 months; ${ }^{3}$ Compared with weight before cancer treatment; ${ }^{4}$ Treated by physiotherapist, nurse, or lymph therapist. ${ }^{5}$ Not included in the multivarable analysis due to $p$ was not $<0.10$ in the univariable analysis

the relationship between fecal leakage and the dependent variable frequency of practicing physical was still significant $(p=$ 0.105 , adjusted models, Table 4).

\section{Physical activity in women with different sociodemographic and clinical characteristics}

According to the multivariable analysis, widows or single women, women who had just an elementary school level of education, smokers, and women with lymphedema without receiving lymphedema treatment were more likely to practice physical activity less often than once a week compared with the other women.

\section{Physical activity in relation to quality of life and depressed and anxious mood}

The women practicing physical activity at least once a week reported better quality of life (md 5, IQR 4-6) and lower frequency of depressed mood (md 3, IQR 2-5) compared with women practicing physical activity less than once a week (quality of life: $\mathrm{md} 4 \mathrm{IQR} 3-5, p<0.001$, depressed mood: md 3, IQR 2 $-5, p=0.044)$. The observed tendency for women practicing physical activity at least once a week to experience anxious mood less frequently was not statistically significant (md 3, IQR 2-5 versus md 4, IQR 2-5, $p=0.071$ ) (Fig. 2).

\section{Discussion}

In summary, we found that one-third of female pelvic cancer survivors practiced physical activity less than once a week. Female cancer survivors experiencing a large volume of fecal leakage were less likely to practice physical activity compared with survivors without leakage and a clear similar trend was seen among those experiencing urinary leakage. Cancer survivors who had just an elementary school level of education, smokers, and survivors diagnosed with lymphedema without receiving lymphedema treatment practiced less physical activity than others. Survivors practicing physical activity at least weekly experienced better quality of life and less frequent experienced depressed mood than others.

The observation that one-third of the female pelvic cancer survivors practiced physical activity less than weekly tells us that these women may need more support in leading them to practice physical activity and even to help them understand the beneficial health effects of physical activity [1]. The frequency of physical activity in this third of the women was much lower than the recommended level of weekly physical activity for all survivors [10]. Several studies report low adherence to the physical activity recommendations $[3,4,15,28]$. Almost all $(96 \%)$ of 285,825 cancer survivors in general did not meet recommended physical activity guidelines 5 years after their cancer diagnosis [28]. Onethird of 600 colorectal cancer survivors met physical activity guidelines while almost half were completely sedentary [3], in line with other observations [15]. Forbes and co-workers reported that $42 \%$ of breast, prostate, and colorectal cancer survivors $(n=741)$ met physical activity guidelines, with no differences among the cancer types [4]. However, our observations on female pelvic cancer survivors indicate that female cancer survivors seem to adhere to recommendations of weekly physical activity to a lower extent than male pelvic cancer survivors and other types of female cancer survivors. Prostate cancer survivors were more likely to meet physical activity guidelines (30\%) than gynecological pelvic cancer survivors (12\%) [29]. Furthermore, Irwin and co-workers reported that $72 \%$ of 1223 breast cancer survivors, i.e., female cancer survivors not exposed to the leakage syndrome, practiced the recommended $\geq 150 \mathrm{~min}$ a week of moderate to vigorous intensity physical activity [13].

It is well known from non-cancer populations that urinary [30] or fecal [31] leakage is a barrier for physical activity. Our study confirmed that pelvic cancer survivors who experienced fecal leakage also practiced less physical activity compared with others. According to the univariable analysis, survivors experiencing urinary leakage practiced less physical activity than women not experiencing urinary leakage. However, in the multivariable analysis, fecal leakage explained a greater part of the variation in frequency of physical activity. Women with urinary 


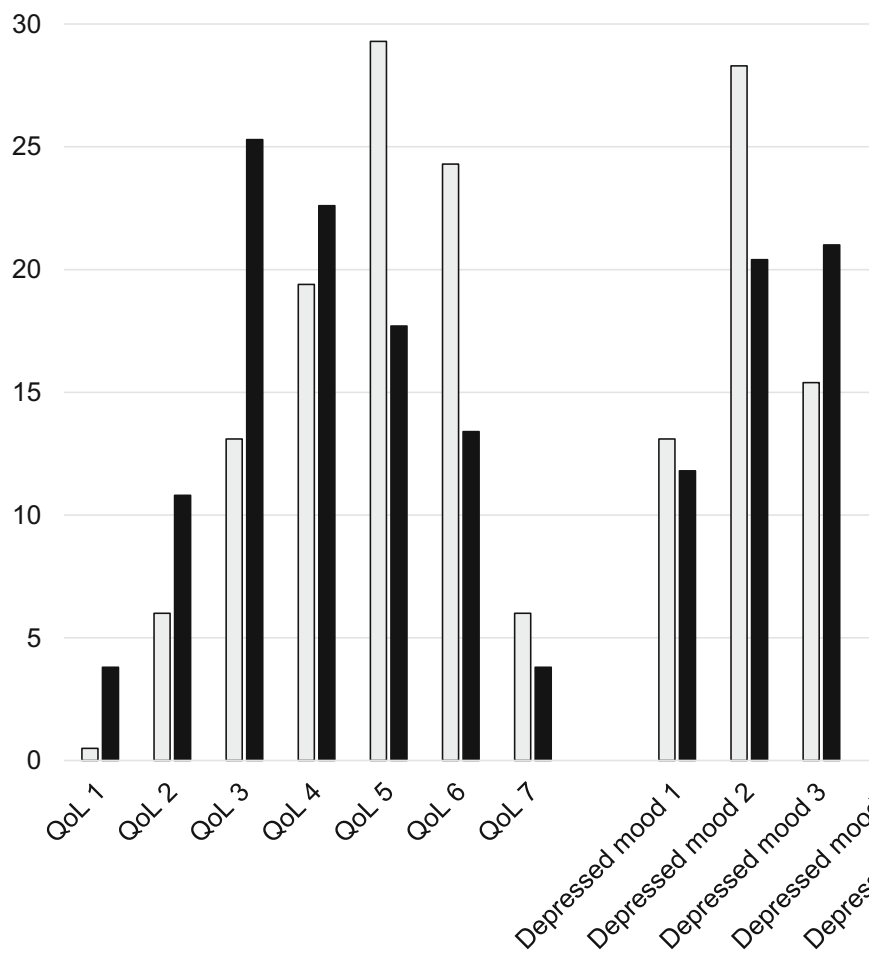

$\square$ Practiced physical activity at least once a week

Fig. 2 Grading of QoL (Quality of Life: 1; No quality of life to 7; Best possible) and frequency of depressed and anxious mood $(1 ;$ Never to 7 ; All the time) in female pelvic cancer survivors practicing physical activity

leakage were more likely to also experience fecal leakage (35\%) than women without urinary leakage (24\%). Thus, urinary leakage may still be a contributing factor to a low level of physical activity, but fecal leakage was a stronger predictive variable. In non-cancer Americans aged 20-85 years $(n=2565)$, higher severity of fecal incontinence was associated with less frequent objectively measured moderate to vigorous physical activity [31]. Gynecological cancer survivors experiencing emptying of all stools without forewarning had a tendency to be more likely to practice physical activity less than weekly (63\%) compared with those without that experience (74\%) [20]. In non-cancer women $(n=41,000)$, a quarter of elderly women and a third of mid-age women avoided vigorous physical activity because of urinary leakage [32]. Furthermore, the proportion perceiving that urinary leakage was a barrier to physical activity ranged from $9 \%$ in women experiencing slight leakage severity to $85 \%$ in women experiencing severe leakage, in $n=3364$ non-cancer women, aged 18 to 60 years [33]. Our study design did not allow us to reveal if it is a causal relation or not between the leakage syndrome and the reduced level of physical activity. Health care professionals may hypothesize that lack of physical activity would cause weaker pelvic floor muscles and thus induce leakage. However, no association between physical activity level and

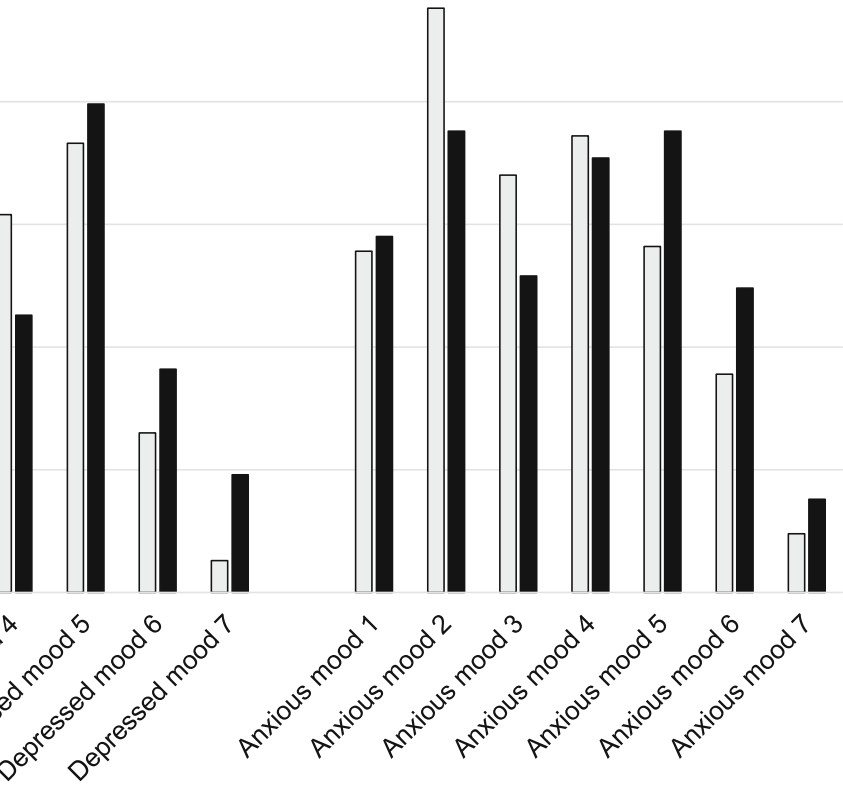

- Practiced physical activity less than once a week

at least once a week or less than once a week. Of 578 women delivering physical activity data, 558 women delivered data on QoL, 559 on depressed mood, and 561 on anxious mood

pelvic floor muscle strength and endurance has been reported among non-cancer women $(n=58)$ [34]. Based on previous findings [20, 22, 30-34], it seems more plausible that the leakage induced reduced physical activity.

The findings that survivors who smoke and/or are less well educated practiced less physical activity are in line with findings among non-cancer general populations [35-37] and among cancer survivors participating in rehabilitation groups [29]. We observed that those diagnosed with lymphedema who received lymphedema treatment practiced more physical activity than the others, even more than women without lymphedema. The fact that rehabilitation professionals probably had encouraged physical activity [10], particularly among survivors with lymphedema, may explain this. Physical activity may improve both objective and subjective parameters of secondary lymphedema and is an important part of lymphedema-treatment [38].

Not surprisingly [33], pelvic cancer survivors practicing physical activity at least weekly reported better quality of life and less often depressed mood than women practicing less physical activity, which seems to be an important finding from our routine-care study context, in light of the great health benefits of physical activity reported in reviews $[1,6]$. We have not found any study reporting the relationship between 
low physical activity and low quality of life among female pelvic cancer survivors suffering from fecal or urinary leakage. However, among breast cancer survivors, increased physical activity reduced clinician-rated depressed mood and improved quality of life [39]. Furthermore, practicing physical activity was related to reduce depressed mood in non-cancer general populations [40, 41]. In a recent study of 1.2 million Americans, individuals who exercise reported 1.49 fewer days of poor mental health within the previous month compared with those who did not exercise [40]. A meta-analysis (92 studies, total $n=4310$ ) found a moderate effect of physical activity for reducing depression [41]. Finally, in non-cancer female general populations, leakage often decreases quality of life. When leakage is treated, quality of life improves [42].

We adopted the hierarchical step-model for causation of bias [43] to review our methodology to limit the risk of confounding factors that may hide an actual association between the variables studied when no real association between them exists. The relationship between the independent variable amount of fecal leakage and the dependent variable frequency of physical activity was still valid after adding the other independent variables to the analysis, which were selected based on previous data on potential moderators of physical activity [10, 29, 35-38]. Regarding misrepresentation, non-participation may induce selection-induced bias. Since we have no information on the non-participating survivors, a strength of our study is that the response rate was $85 \%$. The third step of the hierarchical step-model [43] covers bias induced by misclassification due to incorrect data. A fundamental part of our study was thus the validity of the clinimetric [44] study questionnaire, which was developed according to established [24, 25] previously described methodology [45]. Self-reported questions are the most common and cost-effective measurement of physical activity that can be used in large samples [46]. The risk of recall bias and over and underestimation of physical activity would have been eliminated using accelerometery [46, 47]. However, we found that using accelerometery induces too great a burden on the patient $[46,47]$ and we therefore adopted self-reported physical activity question. We based the cut-off for categorizing the variable on our knowing that physical activity guidelines propose weekly physical activity [10]. However, a limitation is that we registered only the frequency of moderate level physical activity, not the duration. We thus do not know if the female pelvic cancer survivors who practiced physical activity at least weekly adhered to physical activity guidelines for cancer survivors $[10,11]$. However, we clearly know that they practiced physical activity more frequently than the women practicing physical activity less than weekly. Our methodology to collect data in a limited duration of calendar time but with varying length of follow-up time gives us the possibility to depict the trajectory of late effects (manifestations of treatment-induced cancer survivorship diseases and states) without the measurement-induced problems (bias) that may happen when a certain manifestation repeatedly is measured in the same individual. Moreover, we avoid the increase over time in attrition that by and large always happens when the same individuals are followed over time. When we do not stratify according to length of follow-up, we calculate a weighed value for 648 months of follow-up. The women received the study questionnaire by postal mail and answered it in privacy, which reasonably lowers the risk of potential therapist-induced bias. Ordinal data were analyzed by methods appropriate for the ordinal and category nature of the data [48]. We did not include the variables quality of life, depressed mood, and anxious mood in the analysis as possibly explaining the variation in physical activity since we do not know the direction of the relationship between quality of life, depressed mood, and physical activity. We selected only characteristics that reasonably could not be consequences of physical activity.

In conclusion, the survivors practicing weekly physical activity experienced better QoL and experienced depressed mood less frequently than the others. Our results indicate that it is important for cancer care professionals to provide extra support to subgroups of pelvic cancer survivors who practice less physical activity, to help them to maintain the best possible quality of life, and to lower the frequency of depressed mood. We found a covariation between physical activity and fecal leakage. And a clear similar trend was seen among those experiencing urinary leakage. We are uncertain to what extent the leakage leads to reduced physical activity and to what extent (in the other way) physical activity can be correlated with muscular exercise of the pelvic floor, which in turn leads to a reduced incidence of fecal leakage or urine leakage. Our results, however, indicate that there is a logical foundation (rationale) to try pelvic floor training in various ways to reduce the occurrence of leakage and thereby increase the possibilities of living a good life.

Acknowledgments We would like to thank all the pelvic cancer survivors who participated in this study, Elisabeth Bystedt for extensive work in collecting medical record data, Sussanne Börjeson for valuable comments, and Henrik Hedevik for valuable contributions in the statistical analyses. Furthermore, we would also like to thank Lawrence Lundgren for linguistic revision.

Funding information Open access funding provided by Linköping University.

\section{Compliance with ethical standards}

Disclaimer The authors have no financial relationship with the organization that sponsored the research.

Open Access This article is distributed under the terms of the Creative Commons Attribution 4.0 International License (http:// creativecommons.org/licenses/by/4.0/), which permits unrestricted use, distribution, and reproduction in any medium, provided you give appropriate credit to the original author(s) and the source, provide a link to the Creative Commons license, and indicate if changes were made. 


\section{Appendix}

Study-specific questions regarding physical activity, urinary, and fecal leakage, quality of life, depressed an anxious mood.

\section{PHYSICAL ACTIVITY}

Do you practice physical activity?

No

Yes, occasionally

Yes, at least once a month

Yes, at least once a week

Yes, at least three times a week

Yes, at least once a day

FAECAL LEAKAGE

Have you been leaked stools because you could not reach the toilet in time, within the past six months?

No

Yes, occasionally

Yes, at least once a month

Yes, at least once a week

Yes, at least three times a week

Yes, at least once a day

How large volume of faeces do you leak, on average, within the past six months?

Not applicable, I do not leak stools

I only leak so little that it smudges the underwear (soiling)

I leak a small amount of faeces when leaking

I leak a lot of faeces when leaking

All volume of stools

Have you leaked faeces without forewarning within the past six months?

No

Yes, occasionally

Yes, at least once a month

Yes, at least once a week

Yes, at least three times a week

Yes, at least once a day

Have you leaked all faeces without forewarning within the past six months?

No

Yes, occasionally

Yes, at least once a month

Yes, at least once a week

Yes, at least three times a week

Yes, at least once a day 


\section{URINARY LEAKAGE}

Have been wetting yourself because you could not reach the toilet in time, within the past six months?

Not applicable

No

Yes, occasionally

Yes, at least once a month

Yes, at least once a week

Yes, at least three times a week

Yes, at least once a day

Have you been wetting yourself while doing something strenuous (cough, exercise, laughter), within the past six months?

No

Yes, occasionally

Yes, at least once a month

Yes, at least once a week

Yes, at least three times a week

Yes, at least once a day

Have you been wetting yourself without prior feelings of urgency, within the past six months?

No

Yes, occasionally

Yes, at least once a month

Yes, at least once a week

Yes, at least three times a week

Yes, at least once a day

How large volume of urine do you leak?

Not applicable

Small amount

Moderate amount

Large amount (whole bladder volume)

\section{QUALITY OF LIFE, DEPRESSED AND ANXIOUS MOOD}

How has your quality of life been the last six months?

- Put a ring around the number that best suits you -

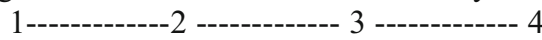

No quality of life at all<smiles>[13S][13S]</smiles>

5 ---------------6

Have you felt low or depressed in the last six months?

- Put a ring around the number that best suits you -

$$
1-
$$$$
\text { 1-------------2 }
$$$$
2 \text {------------- } 3
$$$$
3-
$$

$-4$

Never

5

$-6$ $-7$

All the time

Have you felt anxious within the past six months?

- Put a ring around the number that best suits you -

1-------------2 ------------- 3 ------------- 4
Never

$-5$ $-6$ 7

All the time 


\section{References}

1. Segal R, Zwaal C, Green E, Tomasone JR, Loblaw A, Petrella T (2017) Exercise for people with cancer: a systematic review. Curr Oncol 24:290-315

2. Lind H, Waldenstrom AC, Dunberger G, al-Abany M, Alevronta E, Johansson KA, Olsson C, Nyberg T, Wilderang U, Steineck G, Avall-Lundqvist E (2011) Late symptoms in long-term gynaecological cancer survivors after radiation therapy: a population-based cohort study. Br J Cancer 105:737-745

3. Speed-Andrews AE, Rhodes RE, Blanchard CM, Culos-Reed SN, Friedenreich CM, Belanger LJ, Courneya KS (2012) Medical, demographic and social cognitive correlates of physical activity in a population-based sample of colorectal cancer survivors. Eur $\mathbf{J}$ Cancer Care (Engl) 21:187-196

4. Forbes CC, Blanchard CM, Mummery WK, Courneya KS (2014) A comparison of physical activity correlates across breast, prostate and colorectal cancer survivors in Nova Scotia, Canada. Support Care Cancer 22:891-903

5. Caspersen CJ, Powell KE, Christenson GM (1985) Physical activity, exercise, and physical fitness: definitions and distinctions for health-related research. Public Health Rep 100:126-131

6. Sweegers MG, Altenburg TM, Chinapaw MJ, Kalter J, Verdonckde Leeuw IM, Courneya KS, Newton RU, Aaronson NK, Jacobsen PB, Brug J, Buffart LM (2018) Which exercise prescriptions improve quality of life and physical function in patients with cancer during and following treatment? A systematic review and metaanalysis of randomised controlled trials. Br J Sports Med 52:505513

7. GDB (2016) Global, regional, and national comparative risk assessment of 79 behavioural, environmental and occupational, and metabolic risks or clusters of risks, 1990-2015: a systematic analysis for the Global Burden of Disease Study 2015. Lancet 388:1659-1724

8. Cannioto RA, LaMonte MJ, Kelemen LE, Risch HA, Eng KH, Minlikeeva AN, Hong CC, Szender JB, Sucheston-Campbell L, Joseph JM, Berchuck A, Chang-Claude J, Cramer DW, DeFazio A, Diergaarde B, Dork T, Doherty JA, Edwards RP, Fridley BL, Friel G, Goode EL, Goodman MT, Hillemanns P, Hogdall E, Hosono S, Kelley JL, Kjaer SK, Klapdor R, Matsuo K, Odunsi K, Nagle CM, Olsen CM, Paddock LE, Pearce CL, Pike MC, Rossing MA, Schmalfeldt B, Segal BH, Szamreta EA, Thompson PJ, Tseng CC, Vierkant R, Schildkraut JM, Wentzensen N, Wicklund KG, Winham SJ, Wu AH, Modugno F, Ness RB, Jensen A, Webb PM, Terry K, Bandera EV, Moysich KB (2016) Recreational physical inactivity and mortality in women with invasive epithelial ovarian cancer: evidence from the Ovarian Cancer Association Consortium. Br J Cancer 115:95-101

9. Friedenreich CM, Neilson HK, Farris MS, Courneya KS (2016) Physical activity and cancer outcomes: a precision medicine approach. Clin Cancer Res 22:4766-4775

10. Segal R, Zwaal C, Green E, Tomasone JR, Loblaw A, Petrella T (2017) Exercise for people with cancer: a clinical practice guideline. Curr Oncol 24:40-46

11. RCC (2017) Cancer rehabilitation. National Swedish Care Program $2017 \mathrm{http}: / / \mathrm{www}$ cancercentrumse/globalassets/vara-uppdrag/ rehabilitering-palliativ-vard/vardprogram/natvp cancerrehabilitering_2017-04-26_final.pdf Accessed 20 Oct 2018

12. Craike MJ, Hose K, Courneya KS, Harrison SJ, Livingston PM (2013) Perceived benefits and barriers to exercise for recently treated patients with multiple myeloma: a qualitative study. BMC Cancer 13:319

13. Irwin ML, McTiernan A, Bernstein L, Gilliland FD, Baumgartner R, Baumgartner K, Ballard-Barbash R (2004) Physical activity levels among breast cancer survivors. Med Sci Sports Exerc 36: 1484-1491
14. Midtgaard J, Baadsgaard MT, Moller T, Rasmussen B, Quist M, Andersen C, Rorth M, Adamsen L (2009) Self-reported physical activity behaviour; exercise motivation and information among Danish adult cancer patients undergoing chemotherapy. Eur J Oncol Nurs 13:116-121

15. Lynch BM, Boyle T, Winkler E, Occleston J, Courneya KS, Vallance JK (2016) Patterns and correlates of accelerometerassessed physical activity and sedentary time among colon cancer survivors. Cancer Causes Control 27:59-68

16. Hauer-Jensen M, Wang J, Boerma M, Fu Q, Denham JW (2007) Radiation damage to the gastrointestinal tract: mechanisms, diagnosis, and management. Curr Opin Support Palliat Care 1:23-29

17. Bentzen SM (2006) Preventing or reducing late side effects of radiation therapy: radiobiology meets molecular pathology. Nat Rev Cancer 6:702-713

18. Steineck G, Skokic V, Sjoberg F, Bull C, Alevronta E, Dunberger G, Bergmark K, Wilderang U, Oh JH, Deasy JO, Jornsten R (2017) Identifying radiation-induced survivorship syndromes affecting bowel health in a cohort of gynecological cancer survivors. PLoS One 12:0171461

19. Dunberger G, Lind H, Steineck G, Waldenstrom AC, Nyberg T, AlAbany M, Nyberg U, Vall-Lundqvist E (2010) Self-reported symptoms of faecal incontinence among long-term gynaecological cancer survivors and population-based controls. Eur J Cancer 46:606615

20. Dunberger G, Lind H, Steineck G, Waldenstrom AC, Nyberg T, alAbany M, Nyberg U, Avall-Lundqvist E (2010) Fecal incontinence affecting quality of life and social functioning among long-term gynecological cancer survivors. Int J Gynecol Cancer 20:449-460

21. Dunberger G, Lind H, Steineck G, Waldenstrom AC, Onelov E, Avall-Lundqvist E (2011) Loose stools lead to fecal incontinence among gynecological cancer survivors. Acta Oncol 50:233-242

22. Lindgren A, Dunberger G, Enblom A (2017) Experiences of incontinence and pelvic floor muscle training after gynaecologic cancer treatment. Support Care Cancer 25:157-166

23. Monz B, Pons ME, Hampel C, Hunskaar S, Quail D, Samsioe G, Sykes D, Wagg A, Papanicolaou S (2005) Patient-reported impact of urinary incontinence-results from treatment seeking women in 14 European countries. Maturitas 52:24-34

24. Steineck G, Bergmark K, Henningsohn L, al-Abany M, Dickman PW, Helgason A (2002) Symptom documentation in cancer survivors as a basis for therapy modifications. Acta Oncol 41:244-252

25. Bergmark K, Avall-Lundqvist E, Dickman PW, Henningsohn L, Steineck G (1999) Vaginal changes and sexuality in women with a history of cervical cancer. N Engl J Med 340:1383-1389

26. Olsson SJ, Ekblom O, Andersson E, Borjesson M, Kallings LV (2016) Categorical answer modes provide superior validity to open answers when asking for level of physical activity: a cross-sectional study. Scand J Public Health 44:70-76

27. Onelov E, Steineck G, Nyberg U, Hauksdottir A, Kreicbergs U, Henningsohn L, Bergmark K, Valdimarsdottir U (2007) Measuring anxiety and depression in the oncology setting using visual-digital scales. Acta Oncol 46:810-816

28. Smith WA, Nolan VG, Robison LL, Hudson MM, Ness KK (2011) Physical activity among cancer survivors and those with no history of cancer- a report from the National Health and Nutrition Examination Survey 2003-2006. Am J Transl Res 3:342-350

29. Stevinson C, Lydon A, Amir Z (2014) Adherence to physical activity guidelines among cancer support group participants. Eur J Cancer Care 23:199-205

30. Peterson JA (2008) Minimize urinary incontinence: maximize physical activity in women. Urol Nurs 28:351-356

31. Loprinzi PD, Rao SS (2014) Association between fecal incontinence and objectively measured physical activity in U.S. adults. N Am J Med Sci 6:575-579 
32. Brown WJ, Miller YD (2001) Too wet to exercise? Leaking urine as a barrier to physical activity in women. J Sci Med Sport 4:373-378

33. Nygaard I, Girts T, Fultz NH, Kinchen K, Pohl G, Sternfeld B (2005) Is urinary incontinence a barrier to exercise in women? Obstet Gynecol 106:307-314

34. Carvalhais A, Da Roza T, Vilela S, Jorge RN, Bø K (2018) Association between physical activity level and pelvic floor muscle variables in women. Int J Sports Med 39:995-1000

35. Finger JD, Tylleskar T, Lampert T, Mensink GB (2012) Physical activity patterns and socioeconomic position: the German National Health Interview and Examination Survey 1998 (GNHIES98). BMC Public Health 12:1079

36. Crespo CJ, Ainsworth BE, Keteyian SJ, Heath GW, Smit E (1999) Prevalence of physical inactivity and its relation to social class in U.S. adults: results from the Third National Health and Nutrition Examination Survey, 1988-1994. Med Sci Sports Exerc 31:18211827

37. Trost SG, Owen N, Bauman AE, Sallis JF, Brown W (2002) Correlates of adults' participation in physical activity: review and update. Med Sci Sports Exerc 34:1996-2001

38. Baumann FT, Reike A, Reimer V, Schumann M, Hallek M, Taaffe DR, Newton RU, Galvao DA (2018) Effects of physical exercise on breast cancer-related secondary lymphedema: a systematic review. Breast Cancer Res Treat 170:1-13

39. Fisher HM, Jacobs JM, Taub CJ, Lechner SC, Lewis JE, Carver CS, Blomberg BB, Antoni MH (2017) How changes in physical activity relate to fatigue interference, mood, and quality of life during treatment for non-metastatic breast cancer. Gen Hosp Psychiatry 49:3743

40. Chekroud SR, Gueorguieva R, Zheutlin AB, Paulus M, Krumholz HM, Krystal JH, Chekroud AM (2018) Association between physical exercise and mental health in 1.2 million individuals in the USA between 2011 and 2015: a cross-sectional study. Lancet Psychiatry 5:739-746

41. Rebar AL, Stanton R, Geard D, Short C, Duncan MJ, Vandelanotte C (2015) A meta-meta-analysis of the effect of physical activity on depression and anxiety in non-clinical adult populations. Health Psychol Rev 9:366-378

42. Dumoulin C, Cacciari LP, Hay-Smith EJC (2018) Pelvic floor muscle training versus no treatment, or inactive control treatments, for urinary incontinence in women. Cochrane Database Syst Rev 10: CD005654

43. Steineck G, Hunt H, Adolfsson J (2006) A hierarchical step-model for causation of bias-evaluating cancer treatment with epidemiological methods. Acta Oncol 45:421-429

44. Fava GA, Tomba E, Sonino N (2012) Clinimetrics: the science of clinical measurements. Int J Clin Pract 66:11-15

45. Steineck G, Helgesen F, Adolfsson J, Dickman PW, Johansson JE, Norlen BJ, Holmberg L (2002) Quality of life after radical prostatectomy or watchful waiting. N Engl J Med 347:790-796

46. Skender S, Ose J, Chang-Claude J, Paskow M, Bruhmann B, Siegel EM, Steindorf K, Ulrich CM (2016) Accelerometry and physical activity questionnaires - a systematic review. BMC Public Health 16:515

47. Chen KY, Janz KF, Zhu W, Brychta RJ (2012) Redefining the roles of sensors in objective physical activity monitoring. Med Sci Sports Exerc 44:13-23

48. Svensson E (1998) Ordinal invariant measures for individual and group changes in ordered categorical data. Stat Med 17:2923-2936

Publisher's note Springer Nature remains neutral with regard to jurisdictional claims in published maps and institutional affiliations. 